\title{
AVALIAÇÃO AMBIENTAL DO PARQUE MUNICIPAL MAURICIO DE OLIVEIRA, MOSSORÓ/RN
}

\author{
ENVIRONMENTAL EVALUATION OF THE MUNICIPAL PARK MAURICIO DE \\ OLIVEIRA, MOSSORÓ / RN
}

\author{
Paulo César da Silva Santos ${ }^{1}$, Lívia Laiane Barbiosa Alves², Gutierres Silva Medeiros Aquino3, \\ Gleiciana Nascimento de Almeida ${ }^{4}$, Rejane Tavares Botrel ${ }^{5}$, Vincius Gomes de Castro ${ }^{6}$
}

\begin{abstract}
RESUMO
Com objetivo de determinar os pontos positivos e negativos, quantificar e qualificar a vegetação arbórea do Parque Municipal Mauricio de Oliveira, Mossoró/RN, foram realizados a avaliação pós ocupação (APO) e o censo arbóreo completo na área. Através de uma análise Walkthrough (caminhamento), os principais pontos negativos apontados foram pistas de caminhada com larguras inadequadas, falta de planejamento do estacionamento de veículos, falta de iluminação adequada e poluição do rio ApodiMossoró localizado na área do parque. Entre os pontos positivos destacou-se a importância do parque para o lazer da população de Mossoró. A partir do levantamento dos indivíduos arbóreos na área de estudo, registrou-se a ocorrência de 3897 individuos, distribuídas em 12 famílias e 24 espécies, sedo Prosopis juliflora a espécie mais frequente. As plantas exóticas foram predominantes na arborização do parque $(54 \%)$ tanto em espécies (13) quanto em número de indivíduos (3577), o que acaba causando prejuízos ao ecossistema. Observou-se que o parque apresenta problemas ambientais, que precisam ser minimizados ou eliminados.
\end{abstract}

Palavras-chave: Áreas verdes; Parques urbanos; Semiárido.

\section{ABSTRACT}

In order to determine the positive and negative points, quantify and qualify the arboreal vegetation of the Municipal Park of Mauricio de Oliveira, a post occupation assessment (APO) and the complete arboreal census were carried out. Through a walkthrough analysis, the main negatives aspects pointed out were walking trails with inadequate widths, lack of vehicle parking planning, lack of lighting and pollution of Apodi-Mossoró river located within the park area. Among the positive points its highlight the importance of the park for the leisure of the population of Mossoró. From the survey of the arboreal individuals in the study area, 24 species distributed in 12 different families were registred, being Prosopis juliflora the most frequent one. In number, exotic plants were predominant $(54 \%)$ in the afforestation of the park both in species (13) and in number of individuals (3577), which can cause damage to the ecosystem. After the visits and analysis of the park, it was orbserved that it presents environmental problems, that must be minimized or eliminated.

Keywords: Green areas; Urban parks; Semi-arid.

Recebido em 17.06.2017 e aceito em 05.09.2017

1 Graduando em Engenharia Florestal, Universidade Federal Rural do Semi-Árido. Mossoró/RN. Email: paulocesaref@hotmail.com

2 Engenheira Florestal. Mestranda do programa de Pós-Graduação em Ambiente, Tecnologia e Sociedade. Email: liviabarbosa17@yahoo.com

3 Graduando em Engenharia Florestal, Universidade Federal Rural do Semi-Árido. Mossoró/RN. Email: gutierressilva@hotmail.com

4.Graduanda em Engenharia Florestal, Universidade Federal Rural do Semi-Árido. Mossoró/RN. Email: gleiciana.nascimento@outlook.com

5 Engenheira Florestal, Dra. Professora do Centro de Ciências Agrárias da Universidade Federal Rural do Semiárido. Mossoró/RN. Email: rtbotrel@ufersa.edu.br

6 Engenheiro Florestal, Dr. Professor do Centro de Ciências Agrárias da Universidade Federal Rural do Semiárido. Mossoró/RN. Email: vinicius.castro@ufersa.edu.br 


\section{INTRODUÇÃO}

Com o crescimento das cidades, a população urbana necessita de espaços livres e áreas verdes para recreação e lazer, os quais proporcionam o contato com elmentos naturais e/ou a prática de atividades físicas. Tais ambientes proporcionam melhorias nas condições ambientais das zonas urbanas, que se refletem positivamente na qualidade de vida das pessoas, além de desempenhar um papel importante na preservação da flora e da fauna.

Os espaços livres urbanos apresentam três principais funções: ecológicas, estéticas e sociais. A função ecológica envolve a minimização dos impactos causados pela industrialização, além de preservar a fauna da cidade, como as aves, por exemplo, que dependem da arborização para abrigo, nidificação e alimentação. Já a função estética trata da harmonização dos diferentes estilos arquitetônicos existentes e a vegetação, ao passo que a função social representa a democratização dos espaços públicos destinados ao lazer e recreação (LOBODA; DE ANGELIS, 2009).

O estado do Rio Grande do Norte apresenta poucos parques localizados dentro de cidades, que assumem diferentes papeis no contexto urbano, tais como a preservação e conservação de ecossistemas específicos, a possibilidade de realização de pesquisas, suprimento de demandas de lazer e ecoturismo, além de atividades de educação ambiental e esportivas. Destaca-se, no estado, o Parque Estadual Dunas de Natal, considerado o segundo maior parque urbano do Brasil. A sua área é de aproximadamente 1.172 hectares, superado em tamanho apenas pela Floresta da Tijuca, no Rio de Janeiro, que apresenta xxxx hectares. Seu diversificado ecossistema de dunas abriga fauna e flora de grande importância bioecológica e apresenta condições de uso para pesquisa, educação ambiental, lazer e turismo ecológico, além de possuir grande relevância geológico-geomorfológica (IDEMA, 2016).

No município de Natal também está localizado o Parque da Cidade Dom Nivaldo Monte, cuja área é de 64 hectares e está voltado para a realização de atividades de preservação e educação ambiental, como também de eventos artístico-culturais (REBOUÇAS; GRILO; ARAUJO, 2015). Ainda merece destaque o Parque Estadual Mata da Pipa, que ocupa uma área de 290,88 hectares no município de Tibau do Sul, e é objeto de atividades de educação e interpretação ambiental, além de turismo ecológico (IDEMA, 2016).

Contudo, a presença dos maiores parques urbanos no Rio Grande do Norte estão localizados na região litorânea do estado. Neste sentido, ainda existe uma carência na criação de parques que englobem a vegetação típica das regiões semiáridas. Por este motivo, foi criado o Parque Municipal Maurício de Oliveira no município de Mossoró, na região oeste do estado. Inaugurado em julho de 2016, este parque conta com uma área de $78 \mathrm{mil} \mathrm{m}^{2}$ e é 
considerado pioneiro no quesito parques urbanos com vegetação semiárida do Rio Grande do Norte.

O estudo da percepção ambiental torna-se essencial para que se possa compreender melhor as inter-relações entre o homem e o ambiente no qual vive, suas expectativas, satisfações e insatisfações, valores e condutas, como cada indivíduo percebe, reage e responde diferentemente frente às ações sobre o meio (VIANA et al., 2014). Tal fato é essencial para a conservação e preservação das áreas verdes em parques urbanos. Mas para que o processo alcance sucesso, é essencial a integração da população, que passa a se sentir responsável pela conservação e/ou preservação dos recursos, além de demonstrar um sentimento de respeito com relação ao uso e o futuro desse ambiente (REBOUÇAS; GRILO; ARAUJO, 2015).

Diante disso, objetivou-se com este trabalho avaliar os principais aspectos ambientais, infraestruturas e e da vegetação arbórea do Parque municipal Mauricio de Oliveira, Mossoró, $\mathrm{RN}$. Com isto, pode-se fornecer subsídios para estudos posteriores, que visem contribuir para um plano de manejo e preservação da área destinada a conservação do meio ambiente, lazer e atividades físicas.

\section{MATERIAL E MÉTODOS}

\section{Caracterização da área em estudo}

O município de Mossoró localiza-se no interior do estado do Rio Grande do Norte, na mesorregião do Oeste Potiguar e microrregião homônima, Região Nordeste do país, entre as coordenadas geográficas de $-5^{\circ} 12^{\prime}$ latitude e $-37^{\circ} 20^{\prime}$ longitude. Segundo Köppen, o clima local é BSwh' seco e muito quente, com duas estações climáticas: uma seca, que geralmente compreende o período de junho a janeiro, e uma chuvosa, compreendida entre os meses de fevereiro e maio (DIAS et al., 2010).

A vegetação característica onde está localiza do o parque é do tipo Caatinga do Sertão-Árido, mais precisamente uma caatinga do tipo Hiperxerófila, ou seja, uma vegetação de caráter mais seco com abundância de cactáceas e plantas de porte mais baixo espaçadas. O solo da região em estudo estudo são classificados como latossolo vermelho amarelo eutrófico (FERRAZ et al., 2013).

O parque Municipal de Maurício de Oliveira, objeto de estudo, localiza-se na zona central do município, as margens do rio Apodi-Mossoró (Figura 1). A primeira etapa do parque foi inaugurada no dia 01 de julho de 2016, com a finalidade de proteger os recursos naturais, 
proporcionar condições de bem-estar ao público, garantir a prática de atividades desportivas, sociais e lazer para a população. O parque é o único urbano da cidade, aberto à população todos os dias da semana, das $6 \mathrm{~h} 00$ às $21 \mathrm{~h} 00$. Apesar disso, ainda não existem normas de uso ou regulamento específico para atividades realizadas no local. Foi entregue parte da infraestrutura planejada, sendo esta composta pela pista de cooper, academia da terceira idade, área para convivência, guarita e iluminação do parque. O projeto está regulamentado pela Lei municipal № 3.372, de 29 de janeiro de 2016, que dispõe sobre a parceria entre a Prefeitura de Mossoró e uma empresa privada na construção do local.

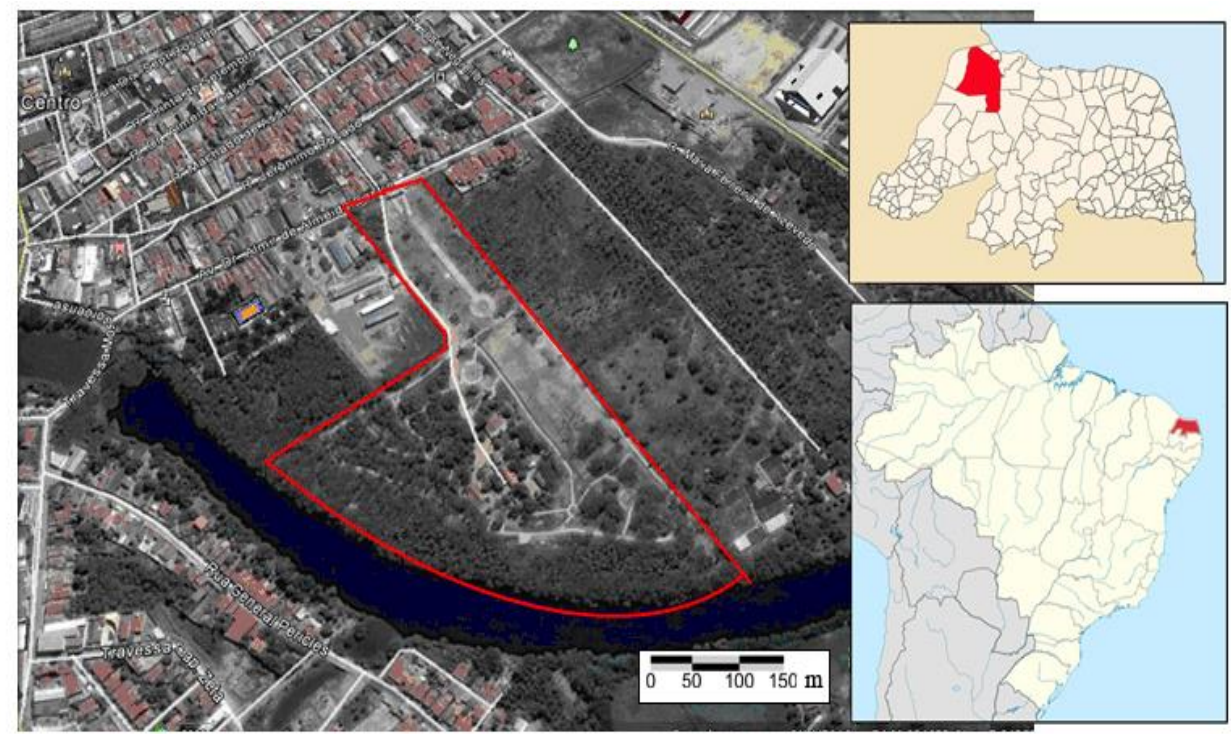

Figura 1. Área do Parque Municipal Maurício de Oliveira, Mossoró/RN

Fonte: Google Earth (2016)

Figure 1. Area of Municipal Park Maurício de Oliveira, Mossoró / RN

A vegetação existente no parque é constituída por espécies exóticas que invadiram a área de mata ciliar e algumas espécies arbóreas nativas remanescente. Além disso, existe na parte central do parque, exemplares plantados de Craibeira (Tabebuia aurea (Silva Manso) Benth. \& Hook. f ex S. Moore).

\section{Coleta de dados}

\section{Avaliação pós ocupação (APO)}

A avaliação pós ocupação foi realizada com o intuito de definir o perfil dos visitantes, sua percepção quanto ao ambiente e infraestrutura local, além de determinar os pontos positivos e negativos do Parque Maurício de Oliveira. De acordo com Ornstein e Villa (2013) a APO pode ser constantemente alterada e composta por diversas técnicas e métodos existentes, devido às particularidades de cada ambiente construído, sendo específica para 
cada estudo de caso. Neste estudo, foram utilizados dois grupos de instrumentos da APO: (1) Observação - roteiro para análise Walkthrough (caminhamento) e (2) Questionários questionário de opinião do usuário.

A aplicação da análise Walkthrough baseou-se na metodologia indicada por Villa, Saramago e Garcia (2015) na qual os pesquisadores fizeram um passeio seguindo um roteiro orientado e registrando os pontos positivos e negativos por meio de observação direta, anotações e registro fotográfico através de um olhar técnico. Com base nestes registros foi realizada a análise SWOT, que envolveu o levantamento das forças (strengths) e fraquezas (weaknesses) do parque, e as oportunidades (opportunities) e ameaças (threats) (SAMARAGO; GARCIA, 2015).

Em uma segunda etapa do trabalho, os usuários do parque foram convidados a responder um questionário. $\mathrm{Na}$ área de estudo ainda não existe controle do número de visitantes por período. Portanto, foi definida uma amostra de 100 visitantes no período de dezembro de 2016 a janeiro de 2017, considerando o fluxo observado nos finais de semana. Aos 100 entrevistados foram feitos questionamentos sobre sua faixa etária, grau de escolaridade e renda média, com o objetivo de traçar um perfil dos frequentadores do parque. Concomitante à determinação do perfil dos usuários, foi solicitado aos informantes que atribuíssem notas a determinados aspectos observados, para se conhecer a opinião da população sobre o parque. Os aspectos questionados incluíram: vegetação, área de lazer, pista de corrida, estacionamento e acessibilidade. A frequência de visitação e a satisfação dos usuários também foram investigadas nesta etapa da pesquisa.

\section{Avaliação da vegetação arbórea do parque}

A vegetação arbórea do parque foi avaliada por meio de um levantamento qualiquantitativo. Para tanto, foi realizado o inventário por enumeração completa, ou seja, o censo arbóreo, por meio do qual identificou-se todos os indivíduos com altura $\geq 1 \mathrm{~m}$ dentro do parque. O reconhecimento das espécies foi realizado inicialmente em campo por seu nome vulgar, com base nos conhecimentos dendrológicos da equipe de levantamento. O material botânico, mesmo quando somente em estado vegetativo, foi coletado e herborizado para identificação das espécies, utilizandose a literatura específica, o auxílio de especialistas botânicos e a comparação com exsicatas depositadas no Herbário da UFERSA (Universidade Federal Rural do Semi-Árido). O sistema adotado para a classificação e identificação foi o APG III (2009). As espécies registradas foram ainda classificadas quanto a sua origem, em exóticas ou nativas (espécies que não ocorrem espontaneamente ou que ocorrem espontaneamente no bioma Caatinga, onde a cidade de Mossoró está inserida). 


\section{RESULTADOS E DISCUSSÃO}

As observações geradas durante a análise Walkthrough foram usadas para a elaboração da análise SWOT (Tabela 1).

Tabela 1. Análise da matriz SWOT realizada para o Parque Maurício de Oliveira, Mossoró, RN Table 1. SWOT matrix analysis performed for Parque Maurício de Oliveira, Mossoró, RN

\begin{tabular}{|c|c|}
\hline Forças & Fraquezas \\
\hline $\begin{array}{l}\text { Área disponível para lazer } \\
\text { Equipamentos de academia em bom estado } \\
\text { Brinquedos em bom estado } \\
\text { Espaço disponível para correções } \\
\text { Boa frequência de visitantes }\end{array}$ & $\begin{array}{l}\text { Solo exposto } \\
\text { Pistas de cooper com largura inadequada } \\
\text { Pista de utilização simultânea (caminhada, } \\
\text { bicicleta, patins etc) } \\
\text { Falta de sinalização nos estacionamentos } \\
\text { Falta de iluminação } \\
\text { Poluição do rio Apodi-Mossoró }\end{array}$ \\
\hline Oportunidades & Ameaças \\
\hline $\begin{array}{l}\text { Área livre apta para reformas } \\
\text { Participação do público em ações de educação } \\
\text { ambiental }\end{array}$ & $\begin{array}{l}\text { Perigo de assaltos } \\
\text { Perigo de acidente entre diferentes usuários da } \\
\text { pista de cooper } \\
\text { Perigo de acidente envolvendo veículos no } \\
\text { estacionamento do parque } \\
\text { Possibilidade de erosão do solo }\end{array}$ \\
\hline
\end{tabular}

Entre as fraquezas do ponto de vista dos aspectos ambientais, destacou-se a presença de vários trechos de solo exposto (Figura 2a), que com a ação do vento gera problemas aos visitantes relacionados ao excesso de poeira. Isto está atrelado à distribuição irregular das árvores no parque e ausência de vegetação herbácea e arbustiva, bem como ao baixo número de indivíduos. Além disso, devido à localização da cidade em uma região de intenso deslocamento de ar, o solo exposto, sem o sistema radicular da vegetação para melhora suas condições físicas, naturalmente está sujeito à erosão eólica.

Sobre a infraestrutura do parque, os pontos negativos registrados foram as pistas com largura inadequada (Figura 2a), fato que se agrava principalmente por serem realizadas atividades simultâneas como a corrida/caminhada, esportes utilizando skate, patins, bicicleta, além da presença de visitantes caminhando com animais de estimação. Portanto, o espaço torna-se insuficiente e expõe os ususários ao risco de acidentes como trombadas, atropelamento e quedas. Porém, como uma oportunidade foi constatado que ainda há espaço disponível para a ampliação das pistas, nas próximas etapas da construção.

Outro problema verificado em relação à infraestrutura do parque foi a falta de planejamento do estacionamento de veículos (Figura 2a), visto que não foram observadas placas de sinalização, revestimento asfaltico e a delimitação do espaço para cada veículo. Entre os pontos negativos, também foi observada a iluminação geral inadequada no parque, o 
que ocasiona a ameaça em relação à segurança no local. A falta de iluminação também limita o uso dos equipamentos de ginástica e o campo de futebol, no período noturno.

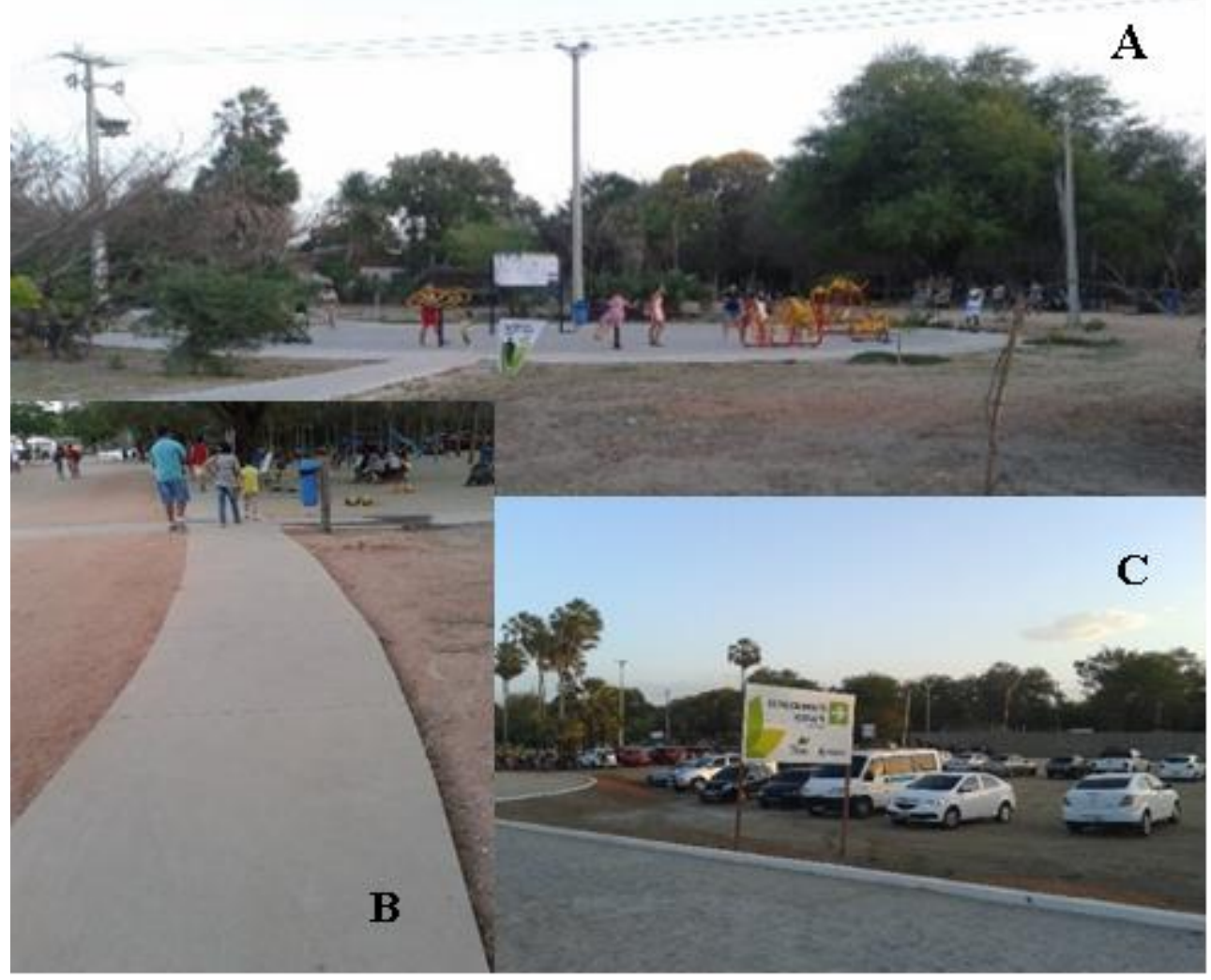

Figura 2. A - Trecho sem vegetação e com solo exposto no Parque Maurício de Oliveira, Mossoró, RN; B - Pista de caminhada presente no parque; C - Estacionamento do parque

Figure 2. A - Extent without vegetation and exposed soil in the Municipal Park Maurício de Oliveira, Mossoró, RN; B - Walking trail in the park; C - Parking lot

A poluição do rio Apodi-Mossoró também foi outro problema reconhecido dentro do parque. Neste rio, a poluição pode ser verificada pela coloração da água, odor e quantidade de lixo presente nas margens e dentro do rio. Também foi observada a presença de processos erosivos e de assoreamento, aliados ao baixo fluxo de vazão e elevado potencial de sedimentação, proveniente dos taludes sem proteção de mata ciliar. Este quadro foi anteriormente constatado por Bezerra et al. (2013).

Entre os pontos positivos, destaca-se a importância do parque para o lazer da população de Mossoró, fato constatado pela forma como este foi adotado pelos visitantes regulares. Durante as visitas realizadas, foi comum a observação de vários grupos de pessoas em piqueniques e ações coletivas visando à recreação, ao lazer e contato com a natureza. Esta boa aceitação da população gera uma oportunidade para que o parque se torne um local de realizações de ações de educação ambiental e valoração do bioma Caatinga.

Com relação ao perfil dos visitantes (Figura 3), de acordo com as entrevistas, observou-se um equilíbrio entre visitantes do sexo masculino (45\%) e feminino (55\%). Sobre a 
faixa etária dos entrevistados, pode ser verificado que o parque mostrou-se mais atrativo para um público jovem, com menos de 30 anos (53\%). Apenas 7\% dos entrevistados tinham mais do que 50 anos de idade. Dos respondentes, 50\% possuem nível superior e, quando perguntados se estavam satisfeitos com o parque, $100 \%$ dos entrevistados responderam que sim.
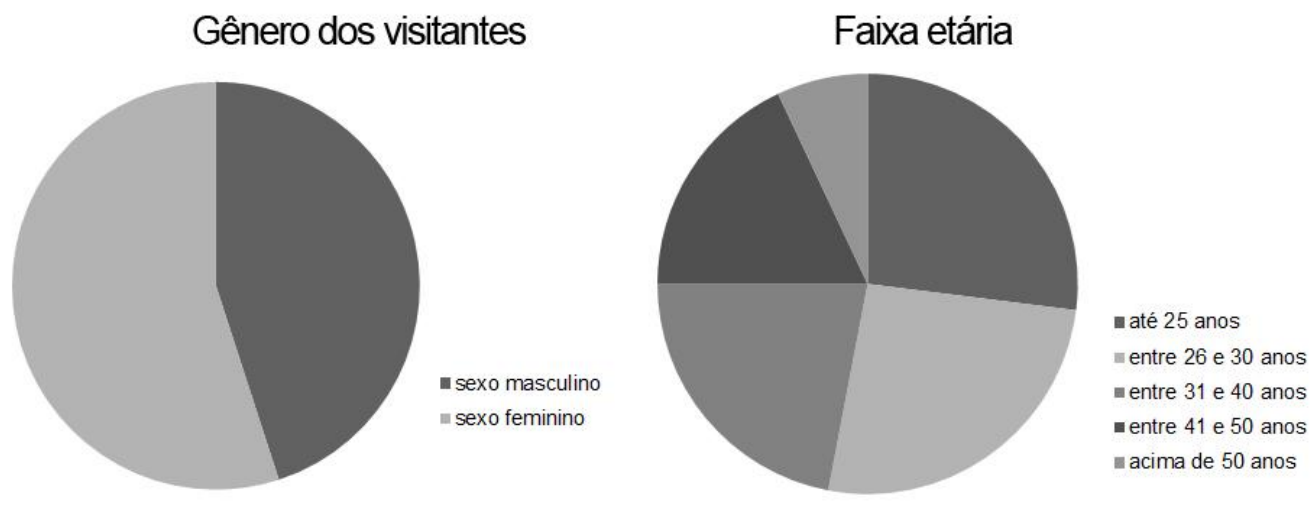

Figura 3. Perfil dos visitantes do Parque Municipal Maurício de Oliveira, Mossoró, RN Figure 3. Visitors' profile in the Municipal Park Maurício de Oliveira, Mossoró, RN

Com relação à frequência dos entrevistados, 25\% visitam o parque diariamente, $43 \%$ semanalmente, $19 \%$ visitam mensalmente e $13 \%$ visitavam o parque pela primeira vez. A média das notas que os entrevistados atribuíram a alguns aspectos destacados no parque, podem ser observados na figura 4.

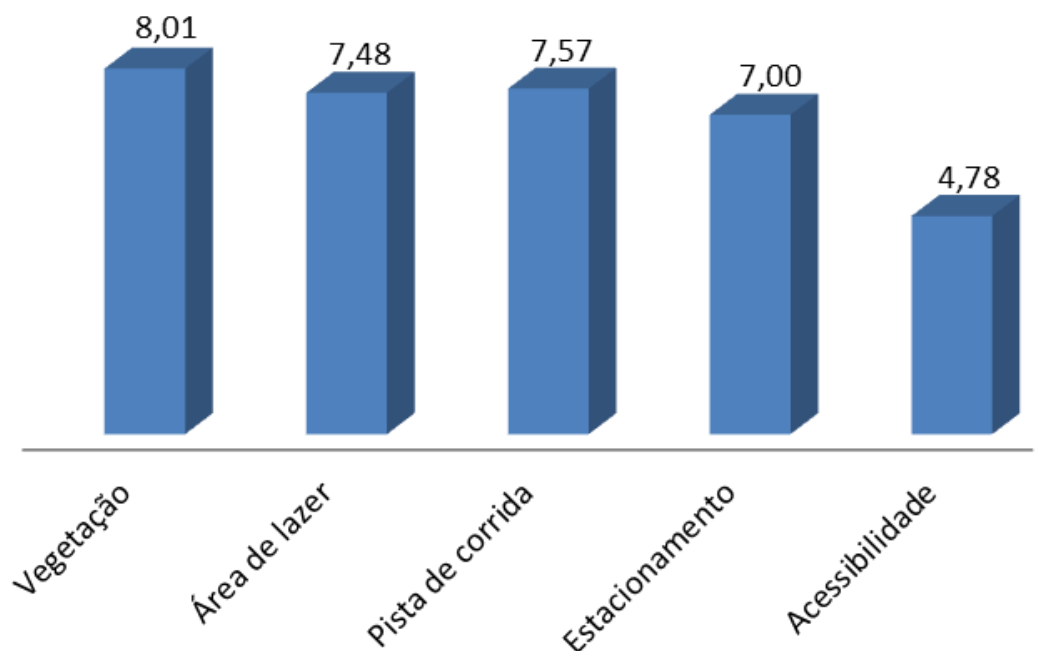

Figura 4. Média das notas atribuídas pelos entrevistados em relação a aspectos observados no Parque Municipal Maurício de Oliveira, Mossoró, RN

Figure 4. Mean of the scores attributed by the interviewees about the aspects observed in the Municipal Park Maurício de Oliveira, Mossoró, RN

Os resultados obtidos por meio dos questionários sugerem que, apesar dos inúmeros pontos negativos observados na análise Walktrhough, a maioria dos entrevistados mostrou-se 
satisfeita com as atuais condições (Figura 4). As maiores notas foram atribuídas à vegetação, área de lazer e pista de corrida, pois não existe diferenças entre estes quesitos. Para todos, a comunidade deu a mesma média: aproximadamente 8,00\%. As menores notas foram atribuídas à acessibilidade, que obteve uma média de notas de 4,78 , onde $19 \%$ da população que visitam o parque atribuíram nota 0 . A falta de atividades de educação ambiental pode ter influenciando nas notas atribuídas pelos entrevistados, tendo em vista que a vegetação do parque se apresenta antropicamente alterada, com números desproporcionais entre espécies exóticas e nativas. O desconhecimento das pessoas sobre as características de uma vegetação nativa conservada, faz com que se sintam satisfeitas somente com a existência de áreas verdes e não propriamente com sua qualidade.

\section{Análise da vegetação}

A partir do levantamento dos indivíduos arbóreos na área de estudo, registrou-se a ocorrência de 24 espécies distribuídas em 12 famílias diferentes (Tabela 2). As espécies de maior ocorrência quanto ao número de indivíduos foram Prosopis juliflora (Sw.) DC. (algaroba) e Copernicia prunifera (Mill.) H.E. (carnaúba), com 3.514 e 212 indivíduos, respectivamente.

As plantas exóticas são predominantes na arborização do parque, tanto em número de espécies (13) quanto em número de indivíduos (3577), este último dado representando 54\% do total amostrados. Esse resultado contradiz Milano e Dalcin (2000), que afirmam que para uma arborização urbana satisfatória é aconselhável que os níveis de espécies exóticas empregadas não ultrapassem $15 \%$ do total.

Espécies exóticas tornam-se ameaça constante, não só para o paisagismo local, mas também para os fragmentos florestais remanescentes do parque e/ou áreas adjacentes, devido à dispersão de suas sementes (BIONDI; MULLER, 2013). Por não apresentarem predadores naturais devido a mudanças de ordem climática e quebra de barreira geográfica, as espécies exóticas introduzidas representam grave ameaça às populações de espécies nativas, que podem ser substituídas pelas primeiras, no espaço e ao longo do tempo (VALERY et al., 2008). A predominância de espécies exóticas já foi relatada em outros trabalhos como por exemplo por Vale et al. (2011), que analisaram a vegetação do Parque da cidade do município de Sobral-CE por meio de um inventário da arborização e constataram que $71 \%$ dos indivíduos eram de origem exótica. No Parque Internacional em Sant'Ana do Livramento/Rivera, Brasil/Uruguai, Araújo et al. (2012) detectaram um elevado índice de espécies exóticas (69\%). 
Tabela 2. Espécies arbóreas com seus respectivos números de indivíduos, registradas no Parque Municipal Maurício de Oliveira, Mossoró, RN classificadas quanto à sua origem - $(\mathrm{N}=$ nativa; $\mathrm{E}=$ exótica)

Table 2. Tree species with their respective numbers, registered in the Municipal Parque Maurício de Oliveira, Mossoró, $R N$ classified according to their origin ( $N=$ native, $E=$ exotic)

\begin{tabular}{|c|c|c|c|c|}
\hline Família botânica & Nome científico & $\begin{array}{l}\text { Nome } \\
\text { comum }\end{array}$ & Origem & $\begin{array}{c}\text { Número } \\
\text { de } \\
\text { indivíduos }\end{array}$ \\
\hline \multirow[t]{3}{*}{ Anacardiaceae } & Spondias lutea L. & Cajarana & $\mathrm{N}$ & 12 \\
\hline & Anacardium occidentale L. & Cajueiro & $\mathrm{N}$ & 2 \\
\hline & Mangifera indica L. & Mangueira & $\mathrm{E}$ & 6 \\
\hline \multirow[t]{2}{*}{ Arecaceae } & $\begin{array}{l}\text { Copernicia prunifera (Mill.) H.E. } \\
\text { Moore }\end{array}$ & Carnaúba & $\mathrm{N}$ & 212 \\
\hline & Cocos nucifera L. & Coqueiro & $\mathrm{E}$ & 10 \\
\hline Bignoniaceae & $\begin{array}{l}\text { Tabebuia aurea (Silva Manso) } \\
\text { Benth. \& Hook. f. ex S. Moore }\end{array}$ & Craibeira & $\mathrm{N}$ & 80 \\
\hline Boraginaceae & $\begin{array}{l}\text { Auxemma oncocalyx (Allemão) } \\
\text { Baill. }\end{array}$ & Pau-branco & $\mathrm{N}$ & 2 \\
\hline Caparaceae & Capparis flexuosa $L$ & Feijão bravo & $E$ & 11 \\
\hline \multirow[t]{2}{*}{ Chrysobalanaceae } & Licania tomentosa (Benth.) Fritsch & Oiti & $\mathrm{N}$ & 2 \\
\hline & Licania rigida Benth. & Oiticica & $\mathrm{N}$ & 1 \\
\hline Combretaceae & Terminalia catappa (Gaertn.) Eichler & Castanhola & $E$ & 1 \\
\hline \multirow[t]{8}{*}{ Fabaceae } & Acacia decurrens Willd. & Acácia-negra & $E$ & 1 \\
\hline & Prosopis juliflora (Sw.) DC. & Algaroba & $E$ & 3514 \\
\hline & Delonix regia (Bojer ex Hook.) Raf. & Flamboyant & $E$ & 1 \\
\hline & $\begin{array}{l}\text { Libidibia ferrea (Mart. ex Tul.) L.P. } \\
\text { Queiroz }\end{array}$ & Jucá & $\mathrm{N}$ & 3 \\
\hline & $\begin{array}{l}\text { Piptadenia stipulacea (Benth.) } \\
\text { Ducke }\end{array}$ & $\begin{array}{l}\text { Jurema } \\
\text { Branca }\end{array}$ & $\mathrm{N}$ & 2 \\
\hline & $\begin{array}{l}\text { Leucaena leucocephala (Lam.) de } \\
\text { Wit }\end{array}$ & Leucena & $E$ & 5 \\
\hline & Mimosa caesalpiniifolia Benth. & Sabiá & $\mathrm{N}$ & 4 \\
\hline & Tamarindus indica L. & Tamarindo & $E$ & 1 \\
\hline Malpighiaceae & Malpighia emarginata DC. & Acerola & $E$ & 5 \\
\hline Malvaceae & Adansonia digitata $\mathrm{L}$. & Boabá & $E$ & 2 \\
\hline Meliaceae & Azadirachta indica A. Juss. & $\mathrm{Nim}$ & $E$ & 19 \\
\hline Oxalidaceae & Averrhoa carambola L. & Carambola & $E$ & 1 \\
\hline Ramnaceae & Ziziphus joazeiro Mart. & Juazeiro & $\mathrm{N}$ & 4 \\
\hline Total & & & & 3897 \\
\hline
\end{tabular}

Vale ressaltar que o parque apresenta área de mata ciliar, considerada no censo arbóreo, que configura uma área de preservação permanente (APP), a qual é constituída por muitos indivíduos de espécies exóticas. O uso dessa categoria de espécies em ambientes ciliares não é uma exclusividade da região nordeste. Assis et al. (2013), analisaram 44 projetos de restauração florestal em matas ciliares no estado de São Paulo implantados entre os anos de 1957 a 2008, e verificaram um aumento na riqueza de espécies plantadas, de 25 espécies, em média, nas décadas de 1970, 1980 e 1990, para 33 espécies entre 2000 e 2008. No 
entanto, os autores anteriormente citados ressaltaram que, nesse montante, as espécies exóticas aumentaram em número de forma proporcional às espécies nativas.

Coelho et al. (2013), considerando florestas no estado do Paraná, também destacaram os muitos problemas relacionados ao uso de espécies exóticas em matas ciliares, sob a luza da legislação pertinente. Para estes autores, a Resolução CONAMA no 429/2011, que estabelece metodologias para recuperação de APPs sem o uso de espécies exóticas, é o ponto de partida para tentar regularizar projetos de restauração.

O problema do excesso da vegetação exótica inserida nos espaços urbanos, vai além das questões ambientais. Gadgil, Berkes e Folke (1993), considerando comunidades rurais e tradicionais, chamam de "conhecimento ecológico tradicional" aquele acumulado no contato de humanos com recursos naturais, termo que referencia principalmente a questão temporal da adaptação e transmissão desse conhecimento entre gerações. Assim, em analogia às comunidades rurais e tradicionais, a presença de muitas crianças, principalmente em idade escolar, em contato com excesso de vegetação exótica no ambiente urbano em que se encontra o parque Maurício de Oliveira, pode ocasionar perda do conhecimento a respeito de espécies nativas ,pelos mais jovens. Isso permite inferir que tal fato pode aumentar ainda mais a preferência por espécies exóticas para plantio em praças, parques e calçadas.

A espécie nativa que obteve maior número de indivíduos foi a Copenicia prunifera (212). Tabebuia aurea foi a segunda espécie nativa com o maior número de indivíduos (80). As espécies nativas são importantes, pois estão adaptadas ao clima da região e desempenham importante função ecológica para o bioma (LOBODA; DE ANGELIS, 2009). No interior de parques na zona urbana, esta vegetação, além de essencial para preservar a biodiversidade e o conhecimento das pessoas em relação à vegetação original das regiões semiáridas, segundo Barbosa, Lopes e Lopes (2015), também seria importante para a sua divulgação e conservação ex situ, no que se refere ao cultivo fora dos perímetros de áreas protegidas. Melo e Piacentini (2011) também ressaltaram em seu trabalho a importância de se valorizar e difundir a flora brasileira na arborização urbana.

O presente trabalho demonstrou que a educação ambiental é umas das principais ferramentas para a manutenção e conscientização da população, através de palestras, oficinas, cursos, plantio de árvores junto com a comunidade, com a finalidade de mostrar a importância da arborização e a necessidade de preservá-la. É de fundamental importância a criação de trilhas ecológicas no parque, proporcionando assim um contato direto com a natureza, visando a valorização, preservação e conservação do ambiente. 


\section{CONCLUSÕES}

A população da cidade de Mossoró considera o Parque Municipal Maurício de Oliveira como uma opção de lazer, devido a determinados pontos positivos. No entanto, o parque apresenta problemas ambientais que precisam ser minimizados ou eliminados.

A vegetação do parque é predominantemente formada por indivíduos arbóreos de espécies exóticas, o que ocasiona prejuízos ao ecossistema.

Neste contexto, a educação ambiental aparece como alternativa essencial para a preservação ambiental, e recomenda-se a substituição das espécies exóticas por espécies nativas e que novos plantios sejam realizados priorizando espécies nativas do bioma Caatinga.

\section{REFERÊNCIAS}

APG III. An Update of the Angiosperm Phylogeny Group Classification for the Orders and Families of Flowering Plants: APG III. Botanical Journal of the Linnean Society, London, v. 161 p. 105-121, 2009.

ARAÚJO, A. C. B.; GRACIOLI, C. R.; GRIMM, E. L.; LONGHI, S. J. Avaliação da florística, do porte e da fitossanidade atual da arborização do Parque Internacional em Sant'Ana do livramento/Rivera, Brasil/Uruguai. Revista da Sociedade Brasileira de Arborização Urbana, Piracicaba, v. 7, n. 1, p. 112-125, 2012.

ASSIS, G. B.; SUGANUMA, M. S; MELO, A. C. G; DURIGAN, G. Uso de espécies nativas e exóticas na restauração de matas ciliares no Estado de São Paulo (1957 - 2008). Revista Árvore, Viçosa, v. 37, n. 4, p. 599-609, 2013.

BARBOSA, L. A.; LOPES, C. G. R.; LOPES, W. G. R. Levantamento das espécies vegetais das praças de São João dos Patos-MA. Revista da Sociedade Brasileira de Arborização Urbana, Piracicaba, v. 10, n. 1, p. 19-29, 2015.

BEZERRA, J. M.; SILVA, P. C. M.; BATISTA, R. O.; PINTO, C. H. C.; FEITOSA, A. P. Análise dos indicadores de qualidade da água no trecho urbano do Rio Apodi-Mossoró em MossoróRN, Brasil. Semina: Ciências Agrárias, Londrina, v. 34, n. 6, p. 3443-3454, 2013.

BIONDI, D.; MULLER, E. Espécies arbóreas invasoras no paisagismo dos parques urbanos de Curitiba, PR. Revista floresta, Curitiba, v. 43, n. 1, p. 69-82, 2013.

COELHO, G. F; SOUSA, R. F. B; GONÇALVES JR, A. C.; CORREIA, A. F.; CORDEIRO, J.; MALAVASI, U. C. Aspectos da legislação ambiental para a vegetação de matas ciliares no estado do Paraná. Acta Iguazu, Cascavel, v. 2, n. 1, p. 22-34, 2013.

DIAS, N. S.; LIRA, R. B.; BRITO, R. F.; SOUSA NETO, O. N.; FERREIRA NETO, M.; OLIVEIRA, A. M. Produção de melão rendilhado em sistema hidropônico com rejeito a dessalinização de água em solução nutritiva. Revista Brasileira de Engenharia Agrícola e Ambiental, Campina Grande, v.14, n.7, p.755-761, 2013. 
FERRAZ R. C.; MELLO, A. A.; FERREIRA, R. A.; PRATA, A. P. N. Levantamento Fitossociológico em Área de Caatinga no Monumento Natural Grota do Angico, Sergipe, Brasil. Revista Caatinga, Mossoró, v. 26, n. 3, p. 89-98, 2013.

GADGIL, M.; BERKES, F.; FOLKE, C. Indigenous knowledge for biodiversity conservation. Ambio, Estolcomo, v. 22, n. 2, p. 151-156, 1993.

INSTITUTO DE DESENVOLVIMENTO SUSTENTÁVEL E MEIO AMBIENTE DO RIO GRANDE DO NORTE (IDEMA). Rio Grande do Norte em dados. Disponível em: < http://www.idema.rn.gov.br/Conteudo.asp?TRAN=ITEM\&TARG=481\&ACT=\&PAGE=0\&PARM= \&LBL=Instituti\%E7\%E3o>. Acesso em: 22 nov. 2016.

LOBODA, C. R.; DE ANGELIS, B. L. D. Áreas verdes públicas urbanas: conceitos, usos e funções. Ambiência, Guarapuava, v. 1, n. 1, p. 125-139, 2009.

MELO, E. F. R. Q.; PIACENTINI, C. A. M. Diversidade da Arborização Urbana no Município de Colorado (RS). Ambiência, Guarapuava, v. 7, n. 2, p. 339-352, 2011.

MILANO, M. S.; DALCIN, E. C. Arborização de Vias Públicas. 1. ed. Rio de Janeiro: Light, 2000.

ORNSTEIN, S. W.; VILLA, S. B. Qualidade ambiental na habitação: avaliação pós-ocupação. São Paulo: Oficina de Textos, 2013.

REBOUÇAS, M. A.; GRILO, J. A.; ARAÚJO, C. L. Percepção ambiental da comunidade visitante do Parque Municipal Dom Nivaldo Monte em Natal/RN. HOLOS, Natal, v. 31, n. 3, p. 109-120, 2015.

VALE, N. F. L.; SOUZA, G. S.; MATA, M. F.; BRAGA, P. E. T. Inventário da arborização do Parque da Cidade do município de Sobral. Revista da Sociedade Brasileira de Arborização Urbana, Piracicaba, v. 6, n. 4, p. 145-157, 2011.

VALERY, L.; FRITZ, H.; LEFEUVRE, J. C.; SIMBERLOFF, D. In search of a real definition of the biological invasion phenomenon itself. Biological Invasions, cidade da revista, v. 10, n. 8, p. 1345-1351, 2008.

VIANA, Á. L.; LOPES, M. C.; LINS NETO, F. A.; KUDO, S. A.; GUIMARÃES, D. F. S.; MARI, M. L. G. Análise da percepção ambiental sobre os parques urbanos da cidade de Manaus, Amazonas. Monografias Ambientais, Santa Maria, v. 13, n. 5, p. 4044-4062, 2014.

VILLA, S. B.; SARAMAGO, R. C. P.; GARCIA, L. C. Avaliação pós-ocupação no programa minha casa minha vida: Uma experiência metodológica. Uberlândia: UFU. 2015. 152p. 